\title{
Tool for Categorizing Remaining Functional Ability of Nursing Home Residents
}

\author{
Kim, Hyun $\mathrm{Ju}^{1} \cdot$ Chang, Sung $\mathrm{Ok}^{2}$ \\ ${ }^{1}$ Department of Nursing, Cheju Halla University, Jeju \\ ${ }^{2}$ College of Nursing, Korea University, Seoul, Korea
}

\begin{abstract}
Purpose: In rapidly aging societies, preserving residents'remaining functional ability (RFA) has been emphasized in nursing home $(\mathrm{NH})$ care. Assessing residents'remaining function is necessary for the planning of this process. This study was done to develop and test categorizing a tool by which the RFA of nursing home residents can be assessed in order to better address their care needs and to support nurses' practice. Methods: This study was conducted in three stages: in-depth interviews with $\mathrm{NH}$ nurses to develop a conceptual framework for categorizing the RFA, construction of preliminary items for the categorizing tool, and then testing the tool's validity and reliability. One hundred ninety-seven residents from ten NHs representing Korea nationwide participated. Results: The RFA of the $\mathrm{NH}$ residents was classified as two dimensions: physical and cognitive function. Fifteen items were developed to categorize the tool for RFA. Correlations with long-term care levels and long term care assessment scores supported the scale's criterion validity. Reliability (Cronbach's $\alpha$, test-retest and inter-rater reliability) was acceptable. Conclusion: This tool can be used to promote effective nursing care by improving the RFA of NH residents. This tool can also be used by nurses in their daily routine $\mathrm{NH}$ care.
\end{abstract}

Key Words: Nursing homes, Aged, Instrument development, Validity, Reliability

\section{INTRODUCTION}

The increase in the size of the elderly population and the rise in the global demand for long-term care services have been well documented [1,2]. In Korea, rapid population aging has impacted Korean nursing care industry. When National Long-Term Care Insurance was introduced in 2008, the number of nursing homes (NHs) in Korea was 1,332; this had risen to 5,005 by 2015 . It is estimated that $2 \%$ of adults over the age of 65 years are living in NHs [3].

Preventing functional decline is an important issue in NHs because this decline can negatively affect the quality of life for older residents [4]. Preserving their remaining functional ability (RFA) is thus a core function of NHs; nevertheless, most $\mathrm{NH}$ residents exhibit a progressive decrease in activity of daily living (ADL), though there is substantial variation in residents' functional abilities. To ensure a high quality of care, improvement in residents' functional ability has been used as a criterion for evaluating $\mathrm{NH}$ performance [5]. Because functional decline is a natural consequence of aging, the quality of long-term care is related to the delay of functional degeneration in the elderly. Improvement in long-term care is a challenging task, even if the functional ability of residents can be increased. As such, the remaining functions of $\mathrm{NH}$ residents must be assessed so that care plans can be devised that will preserve their RFA and changes in their remaining functions can be evaluated.

The long-term care grade determines the service coverage for elderly recipients of long-term care insurance in Korea. This grade is calculated using the Long-term Care Assessment Evaluation Table (LCAET) [6]. The LCAET consists of 104 items that are evaluated once a year for the assessment of the long-term care grade. The evaluation process requires ample time and skilled estimators [7]. However, because NH residents' physical condition and psychosocial characteristics are inextricably linked with

Corresponding author: Chang, Sung Ok https://orcid.org/0000-0003-2710-4291

College of Nursing, Korea University, 145 Anam-ro, Seongbuk-gu, Seoul 02841, Korea.

Tel: +82-2-3290-4918, Fax: +82-2-927-9676, E-mail: sungok@korea.ac.kr

Received: Nov 15, 2018 / Revised: Feb 22, 2019 / Accepted: Mar 25, 2019

This is an open access article distributed under the terms of the Creative Commons Attribution Non-Commercial License (http://creativecommons.org/licenses/ by-nc/3.0), which permits unrestricted non-commercial use, distribution, and reproduction in any medium, provided the original work is properly cited. 
the nursing process, assessing residents' RFA is necessary for planning this process [8].

With the rise in the number of NHs in Korea, the number of new nurses in NHs has increased quickly over a shorter period of time compared to other developed countries. Generally, a registered nurse (RN) at a $\mathrm{NH}$ cares for over three times more residents than in a hospital due to different nursing staffing levels [9]. Assessing and categorizing the residents for their care needs is an important nursing role for RNs in NHs.

Therefore, a categorization tool that can be used as part of routine nursing care in NHs is needed to assess the RFA of residents and to allow care plans to be developed that focus on their remaining functions for developing standardized care plan.

The LCAET is used for establishing the standard plan for long-term care benefits, giving recipients a long-term care grade and outlining types of long-term care benefits with regards to long-term care insurance. The LCAET is the useful assessment tool for planning long term care plan but not suitable for everyday use by nurses of NHs, because it takes a lot of time, complexity and needs a trained rater. A categorization tool which can guide the individual care plans created by RNs in NHs for residents' daily living is needed.

\section{Objectives}

This study attempted to develop and test a categorization tool to assess the RFA of $\mathrm{NH}$ residents as part of establishing their care needs and to support $\mathrm{NH}$ nurses in developing effective nursing care plans.

\section{METHODS}

\section{Study Design}

To develop the categorization tool, this study was conducted in three stages. The first stage involved developing a conceptual framework for categorizing the RFA of $\mathrm{NH}$ residents. The second stage involved constructing preliminary items for the assessment of the RFA of $\mathrm{NH}$ residents. The third stage tested the validity and reliability of the developed categorization tool for the assessment of NH residents according to their RFA.

\section{Participants}

During the first stage, a conceptual framework for categorizing the RFA of $\mathrm{NH}$ residents was derived from a previous research [10] and an analysis of in-depth interviews with skilled NH nurses. As a large sample was considered unnecessary for the in-depth interviews [11], we conducted 11 in-depth interviews with seven RNs from NHs. Because the professional experience was considered an important factor in their responses to the interview questions, the mean professional career length of the participated RNs was 17.0 years. In second stage, content validity was tested by nine gerontological nursing experts who were four professors of nursing science and medical science and five $\mathrm{NH}$ directors with doctoral degrees in nursing. In third stage, for testing the validity and reliability of the developed categorization tool of RFA, one hundred ninety-seven $\mathrm{NH}$ residents in the ten selected NHs participated. The initial items of the developing assessment tool were eighteen. For validity test, a desirable sample size includes more than seven times the total number of items [12], we recruited 219 participants. The participants who were over ten times the number of items were recruited considering the dropout rate. Twentytwo participants were dropped by failing to retract participation or complete measurement.

\section{Data Collection}

At the first stage, eleven in-depth interviews were conducted using open-ended semi-structured questions focusing on the assessment factors employed by nurses to evaluate and preserve the RFA of $\mathrm{NH}$ residents.

The second stage involved constructing preliminary items for the assessment of the RFA of NH residents. We derived these items from an analysis of the 11 interviews conducted during the first stage. Content validity was tested by two times each consulting nine experts (four professors of nursing science and medical science and five $\mathrm{NH}$ directors with doctoral degrees in nursing). From the identified items for the assessment of the RFA of $\mathrm{NH}$ residents, an initial eighteen-item assessment tool was designed.

During the third stage, data was collected from $\mathrm{NH}$ residents in Korea (Seoul and four of the nine Korean provinces: Gyeonggi, Gangwon, Chungcheong, and Jeju). The raters independently measured the remaining function of the residents by the developed categorizing tool. For testing inter-rater reliability, two or three RNs of each participants NHs were recruited for raters. Workshops explaining how to use the proposed assessment tool were held before the data collection took place. The raters all had more than three years' professional experience as RNs, had worked in an $\mathrm{NH}$ as an $\mathrm{RN}$ for an average of 
4.3 years, and had a mean age of 48.1 years. Participants were recruited in the 10 selected NHs. To be eligible for the study, they had to be more than 60 years old, a beneficiary of National Long-term Care Insurance, and a voluntary participant who had provided an informed consent.

Because the assessment of remaining ability would typically be carried out by several nurses within a single $\mathrm{NH}$, it was important to confirm inter-rater reliability using an equivalence test. Thus, two nurses at each $\mathrm{NH}$ independently measured the same subjects once each, and a correlation analysis was then conducted on the paired nurses. Eighty-seven participated residents of total 197 participants were evaluated by two each nurse independently for testing inter-rater reliability. In order to verify test-retest reliability, one hundred-ten participated residents of total 197 participants were evaluated by one nurse twice every other day for testing test-retest reliability. Table 1 presents the general characteristics of the 197 residents from $10 \mathrm{NHs}$ who participated in this analysis. The mean age of the participants was 80.1 years old, with $79.2 \%$ of the participants were women.

\section{Data Analysis}

In the first stage, content analysis of the interviews and review of previous research data were conducted to develop the conceptual framework. Because the interviews and analysis were conducted simultaneously, additional information to be collected in follow-up interviews could be determined based on the analytical results. For this reason, one of the participating nurses was interviewed three times, and two were interviewed twice.

During the second stage, we calculated the item-level content validity index (CVI) using a 4-point ordinal rating scale (1=irrelevant, $2=$ unable to assess the relevance without item revision, $3=$ relevant with minor alterations, $4=$ extremely relevant). Three items received a score under the minimum of $80 \%$, indicating agreement between the reviewers that these items scored under 3 points; thus, they were excluded.

In the third stage, we analyzed the collected data using IBM SPSS 22.0. The descriptive statistics were analyzed, the internal consistency of the developed tool was tested using Cronbach's $\alpha$, and the inter-rater reliability and test-retest reliability of the developed categorization tool were tested using Spearman's rho.

LCAET is a valid tool scoring the elderly's long-term care needs and has four factors of physical, social, and intellectual functions and nursing measures taken which means their special nursing care need such as catheter-
Table 1. General Characteristics of the Participants (NH residents)

$(N=197)$

\begin{tabular}{|c|c|c|}
\hline Characteristics & Categories & $\begin{array}{c}\mathrm{n}(\%) \text { or } \\
\mathrm{M} \pm \mathrm{SD}\end{array}$ \\
\hline Gender & $\begin{array}{l}\text { Female } \\
\text { Male }\end{array}$ & $\begin{array}{r}156(79.2) \\
41(20.8)\end{array}$ \\
\hline $\begin{array}{l}\text { Long-term care } \\
\text { grade }\end{array}$ & $\begin{array}{l}\text { Grade } 1 \\
\text { Grade } 2 \\
\text { Grade } 3 \\
\text { Grade } 4 \\
\text { Missing* }\end{array}$ & $\begin{array}{l}21(10.7) \\
50(25.4) \\
74(37.5) \\
26(13.2) \\
26(13.2)\end{array}$ \\
\hline Age (year) & & $80.12 \pm 8.81$ \\
\hline $\begin{array}{l}\text { Long-term care } \\
\text { assessment } \\
\text { evaluation table }\end{array}$ & $\begin{array}{l}\text { Physical function } \\
\text { Social function } \\
\text { Intellectual function } \\
\text { Behavioral change } \\
\text { Nursing measures taken }\end{array}$ & $\begin{array}{r}27.06 \pm 8.90 \\
27.15 \pm 4.86 \\
4.57 \pm 3.65 \\
3.61 \pm 3.91 \\
0.19 \pm 0.53\end{array}$ \\
\hline ADL & $\begin{array}{l}\text { Dressing } \\
\text { Washing face } \\
\text { Gargling } \\
\text { Bathing } \\
\text { Eating } \\
\text { Changing position } \\
\text { Sitting up } \\
\text { Sitting movements } \\
\text { Moving outside of room } \\
\text { Using the toilet } \\
\text { Bowel continence } \\
\text { Urinary continence } \\
\text { Shampooing }\end{array}$ & $\begin{array}{l}2.10 \pm 0.74 \\
1.99 \pm 0.79 \\
1.85 \pm 0.79 \\
2.61 \pm 0.61 \\
1.68 \pm 0.76 \\
1.73 \pm 0.78 \\
1.79 \pm 0.85 \\
1.96 \pm 0.88 \\
2.06 \pm 0.89 \\
2.22 \pm 0.86 \\
2.10 \pm 0.87 \\
2.11 \pm 0.87 \\
2.49 \pm 0.70\end{array}$ \\
\hline Morse fall scale & & $5.43 \pm 5.43$ \\
\hline MMSE & & $9.27 \pm 9.27$ \\
\hline
\end{tabular}

*No answer; $\mathrm{ADL}=$ Activity of daily living; MMSE=Mini mental status examination.

ization, tube feeding and others [13]. LCAET was used as the golden standard of the developed tool in this study, although it is not suitable for daily assessment. We determined the four factors of LCAET to validity test of the developed tool. Validity was tested by evaluating correlation by Spearman's rho with the LCAET, the Morse Fall Scale (MFS), and the mini mental status examination (MMSE). The risk of falling is increased by physical, emotional, and cognitive factors [14]. The risk of falling falls as the cognitive function decreases, the physical function decreases, the cognitive decline such as dementia and the partial decline of physical function $[15,16]$. Thus, the score of developed tool was compared with MFS which reflected risk for falling and MMSE which reflected mental status.

The long-term care grade for each of the residents was given by the Long-Term Care Needs Certification. The 
cut point for categorizing the residents' groups by their care needs; two dimensions of mobility and cognition were derived, of the developing tool was determined using a Receiver Operating Characteristic (ROC) curve analysis in which the proportion of true positives is plotted against the proportion of false positive for various possible settings of the decision criteria can be used for diagnostic tests with outcomes measured on ordinal, interval, or ratio scales [17].

\section{Ethical Considerations}

The study was approved by Korea university's Institutional Review Board (1040548-KU-IRB-14-99-A-2). We explained the purpose of the study to the participants, who were also informed that participation was voluntary. We assured the participants that the information they provided would remain confidential and obtained informed consent from all participants.

\section{RESULTS}

\section{Developing Assessment Items}

The conceptual framework for the categorization of the RFA of NH residents was developed during the first stage (Figure 1). As a result, physical function focused on mobility and cognitive function were chosen as the main categories of assessment. Three core themes for the assess- ment of NH residents' RFA were identified. "The finding of new nursing problems due to functional change" related to the nurse not only monitoring ADL, but also other health problems such as dysphagia, difficulty in eating, hyperglycemia/hypoglycemia, risk of pressure sores, and depression. The theme "the remaining function varies according to the cognitive state even though the level of physical function remains the same" arose from similar comments repeated in several interviews, with these comments re-coded as communication ability, recognition, aggressiveness, and response. The theme "the focus of nursing depends on the level of mobility" also derived from similar and repeated comments; we found that the nursing plan changes based on how well the residents can move themselves around. After this content analysis, 18 items for the assessment of NH residents' RFA were derived, including the degree of bedriddenness, in-bed motility, movement out of bed, grip strength, walking, communication, orientation, aggression, and response.

Following consultation with the nine gerontological nursing experts, the categorization tool was reduced to 15 items with an agreement over. 8 by calculating the CVI. The three deleted items were "(S)he can move using a wheelchair or stretcher," "(S)he can use a spoon or a pencil in her/his hand," and "(S)he can move from bed independently, but (s)he needs the support of helpers for safety."

The assessments included the items of mobility and the items of cognition, with rating scales of 0 to 6 and 0 to 9 , respectively. The developing categorization tool consisted

Assessment of Remaining Functional Ability of NH Residents

Nursing Need due to Functional Change
Remaining Ability Diversity according to Cognition
Various Focused Care according to Mobility

\section{Assessment for Categorizing the Residents}

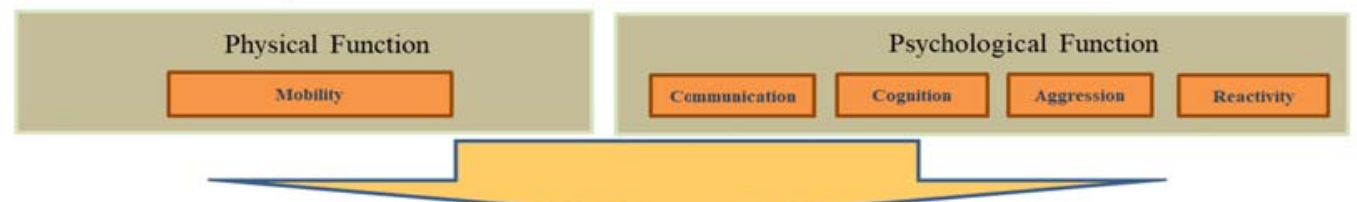

\begin{tabular}{|l|c|c|c|}
\hline $\begin{array}{c}\text { Declining Physical } \\
\text { and Cognitive } \\
\text { function }\end{array}$ & $\begin{array}{c}\text { The Type of Resident with } \\
\text { and Bedridden }\end{array}$ & $\begin{array}{l}\text { Severe Dementia and } \\
\text { Bedridden }\end{array}$ & $\begin{array}{l}\text { Severe Dementia with } \\
\text { Behavioral Problem, but } \\
\text { almost intact phycical } \\
\text { function }\end{array}$ \\
\hline
\end{tabular}

Figure 1. Conceptual framework. 
with the six mobility items and the nine cognition (Table 2). The shaded four items of nine cognitive items; "selfharm with abnormal behavior", "verbally attacking others", "physically attacking others", and "apathy or no reaction" need to reverse coding.

\section{Validity}

To determine the criterion validity of the proposed categorization tool, a correlation analysis between the tool and both the long-term care grade and the LCAET score was conducted.

The correlation between the developed categorization tool and individual categories of the LCAET were found to be statistically significant, thus verifying the criterion validity of the tool (Table 3). To determine the discriminate validity of the proposed categorization tool, correlation between the developed categorization tool and LCAET, MFS and MMSE were analyzed. The correlation was moderate but statistically significant. The developed tool and physical function $(\mathrm{r}=-.70, p<.001)$, social function $(\mathrm{r}=-.50, p<.001)$, intellectual function $(\mathrm{r}=-.39, p<.001)$ and nursing measure taken $(\mathrm{r}=-.24, p<.001)$ of LCAET were significantly correlated.

This study used ROC curve analysis to determine the optimal cut point for the categorization tool (Figure 2-A, B). ROC is a probability curve and area under the curve (AUC) represents measure of separability [17]. It tells

Table 2. Categorizing Tools of Remaining Functional Ability

\begin{tabular}{|c|c|c|c|}
\hline Dimensions & Assessment items & Yes & No \\
\hline \multirow[t]{6}{*}{ Mobility } & With support for changing diaper, (s)he able to lift hips by oneself while lying down. & 1 & 0 \\
\hline & When changing positions in the bed, the leg has enough strength to support partial weight. & 1 & 0 \\
\hline & (S)He able to be supported by arm strength when changing positions in bed. & 1 & 0 \\
\hline & With the support of helpers, (s)he able to move from bed into a wheelchair using leg strength. & 1 & 0 \\
\hline & With the support of helpers, (s)he, able to move from bed into a wheelchair using arm strength. & 1 & 0 \\
\hline & (S)He able to walk independently with the support of a walker. & 1 & 0 \\
\hline \multirow[t]{9}{*}{ Cognition } & (S)He can do verbal communication. & 1 & 0 \\
\hline & (S)He can do nonverbal communication to express one's needs. & 1 & 0 \\
\hline & (S)He able to answer to one's own name. & 1 & 0 \\
\hline & (S)He able to recognize one's family member. & 1 & 0 \\
\hline & (S)He able to recognize one's care giver (or primary nurse). & 1 & 0 \\
\hline & (S)He do self-harm with abnormal behavior. & 0 & 1 \\
\hline & (S)He is verbally attacking others. & 0 & 1 \\
\hline & (S)He is physically attacking others. & 0 & 1 \\
\hline & (S)He seems to be apathy or no reaction. & 0 & 1 \\
\hline
\end{tabular}

Table 3. Correlation of RFA with Functional Characteristics of LCAET

$(N=197)$

\begin{tabular}{|c|c|c|c|c|c|c|c|}
\hline \multirow{3}{*}{ Physical function } & \multirow{3}{*}{ Items } & \multicolumn{4}{|c|}{ Long-term care assessment evaluation table (LCAET) } & \multirow[b]{2}{*}{ MFS } & \multirow[b]{2}{*}{ MMSE } \\
\hline & & $\begin{array}{l}\text { Physical } \\
\text { function }\end{array}$ & $\begin{array}{c}\text { Social } \\
\text { function }\end{array}$ & $\begin{array}{l}\text { Intellectual } \\
\text { function }\end{array}$ & $\begin{array}{c}\text { Nursing } \\
\text { measures taken }\end{array}$ & & \\
\hline & & $r(p)$ & $r(p)$ & $\mathrm{r}(p)$ & $\mathrm{r}(p)$ & $\mathrm{r}(p)$ & $\mathrm{r}(p)$ \\
\hline Categorization tool & 15 & $-.70(<.001)$ & $-.50(<.001)$ & $-.39(<.001)$ & $-.24(<.001)$ & $.10(.169)$ & $.44(<.001)$ \\
\hline Mobility & 6 & $-.72(<.001)$ & $-.41(<.001)$ & $-.16(<.001)$ & $-.27(<.001)$ & $.32(<.001)$ & $.25(.001)$ \\
\hline Cognition & 9 & $-.36(<.001)$ & $-.36(<.001)$ & $-.52(<.001)$ & $-.12(<.001)$ & $-.21(.003)$ & $.43(<.001)$ \\
\hline
\end{tabular}

Value: Spearman's rho, ( $p$-value: two-tailed); MFS=Morse fall scale; MMSE=Mini mental status examination. 
how much model is capable of distinguishing between classes. There were two dimensions in the assessment, mobility and cognition. To determine the optimal cut point for mobility, "bedriddenness" from the LCAET was used the gold standard for comparing. The area under the ROC curve (AUC) was .81. At a cut point of 3.5, sensitivity was .93 and specificity was .50 (Figure 2-A). To determine the optimal cut point for cognition, the judgment score of "cognitive decline" from the LCAET was used. The AUC value was .71. At a cut point of 8.5 , sensitivity was .86 and specificity was .55 (Figure 2-B).

\section{Reliability Test}

The inter-rater reliability coefficient for RFA was .77, its Cronbach's $\alpha$ coefficient was .88, and its test-retest reliability coefficient was .89 . As the category of mobility, the inter-rater reliability coefficient was .77, its Cronbach's $\alpha$ coefficient was .92 , and its test-retest reliability coefficient was .92. As the category of cognition, the inter-rater reliability coefficient was .72, its Cronbach's $\alpha$ coefficient was .76, and its test-retest reliability coefficient was .78.

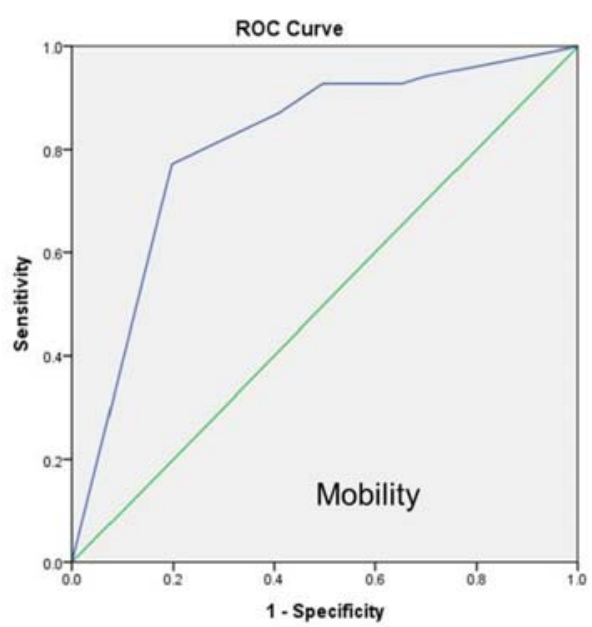

Figure 2-A. ROC curve: mobility.

\section{DISCUSSION}

The developed categorization tool for NH residents was focused their need for nursing care of the remaining functional ability of $\mathrm{NH}$ residents. The concept of preserving remaining abilities of $\mathrm{NH}$ residents is similar to function-focused care (FFC) [18]. FFC and restorative care were emphasized more in American NHs after enacted the Omnibus Budget Reconciliation Act [19]. Since the National Long-Term Care Insurance was implemented and quality evaluation of $\mathrm{NH}$ institutionalized, nursing care for preserving the remaining abilities of $\mathrm{NH}$ residents has been emphasized in Korea.

According to a previous research, the management of the RFA of $\mathrm{NH}$ residents were categorized to five types [10]. Based on the results of our analysis, we propose a modification to four categories for the remaining functional abilities of $\mathrm{NH}$ residents in the RFA (Table 4). As the result of our in-depth interviews regarding the assessment of NH residents' RFA, the four categories that focused mobility and cognition of the $\mathrm{NH}$ residents were derived. We synthesized the results of the previous study [10]. We have developed an RFA categorization tool for

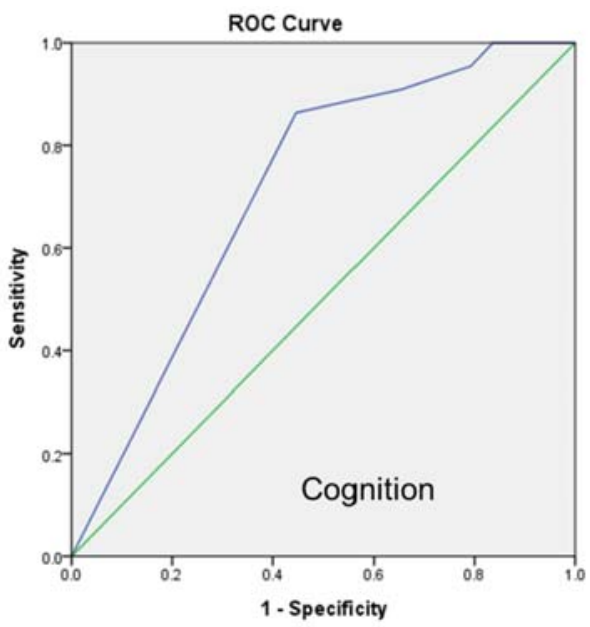

Figure 2-B. ROC curve: cognition.

Table 4. Four Categories for the Remaining Functional Abilities of NH Residents in the RFA*

\begin{tabular}{llll}
\hline \multirow{2}{*}{ Dimensions } & \multicolumn{2}{c}{ Over 4 } & Mobility \\
\cline { 2 - 4 } Cognition & Over 9 & $\begin{array}{c}\text { With declining physical function and moderate } 3 \\
\text { cognitive impairment }\end{array}$ & $\begin{array}{c}\text { Bedridden residents with moderate cognitive } \\
\text { impairment }\end{array}$ \\
\cline { 2 - 4 } & Under 8 & $\begin{array}{c}\text { With severe cognitive impairment and behavior } \\
\text { problems }\end{array}$ & Bedridden residents with intact mental health \\
\hline
\end{tabular}

*The categories of the NH residents derived from the results of Rim et al. [10]. 
assessing and evaluating $\mathrm{NH}$ residents in order to preserve their RFA, and the tool has two dimensions of mobility and cognition.

We examined the validity and reliability of the RFA, a tool for assessing the RFA of NH residents. To insure the internal validity of the RFA, in-depth interviews with RNs who had more than three years of experience in $\mathrm{NHs}$ were used to develop the items in this tool and to improve its usability. The "using a spoon" item was decided on as the last RFA a resident is able to perform based on the in-depth interviews. From this field work, "bathing" was found to be the most dependent ADL and "eating" the most independent ADL; these results agreed with those of previous research [20].

In this study, "remembering one's own name" rather than "remembering the names of family members" is a cognitive function that is maintained until later stages in elderly patients who have significant cognitive decline, while "memory of the names of oneself, family members, and/or intimate friends" was derived as an important factor in assessing residents' cognition from the in-depth interview for developing assessment items. According to the Global Deterioration Scale [21], the first stage of cognitive function is "no cognitive decline," and the sixth stage is "severe cognitive decline (moderately severe dementia)," which is when residents occasionally forget the name of their spouse but can remember their own name. We developed the assessment items derived from nurses' practices and confirmed the recent research outcomes.

$\mathrm{NH}$ residents with memory impairment often do not remember the names of things, persons, or places [22]. Thus, the assessment factors recognized by the nurses in this study and the memory problems perceived by elderly residents in previous research were similar [23].

To test the categorization tool's validity, we analyzed its correlation with the long-term care grade and the LCAET, which consists of 104 items used to evaluate the care that benefit recipients need; the care grade and evaluation score are the current standards for determining the RFA of residents, but the evaluation cycle is longer than one year. Our proposed tool takes less time and is easier for RNs to use than the LCAET.

Additionally, to test the tool's validity, we analyzed its correlation with MFS because residents with a high risk of falling exhibit low cognition and high physical vulnerability, thus this scale also has cognition and physical function as its two main assessment factors [24,25]. As a result, our proposed tool closely reflects the RFA of $\mathrm{NH}$ residents.

We classified the RFA of the residents into two di- mensions; physical and cognitive function. In this study, we analyzed the ROC curves for physical and cognitive function to determine the optimal cut point for the categorization tool based on sensitivity and specificity. ROC curves can determine optimal cut off values using statistical data [26]. We decided the cut-off points by calculating AUC which means the average sensitivity for all values of specificity, and the average specificity for all values of sensitivity [27], but the derived cutoff value could be interpreted as clinically meaningful.

The results of the analysis found that there was a difference between 3 and 4 points for mobility, with 3 points or lower representing residents who are unable to perform out-of-bed activities and 4 points or more describing residents who are able to perform out-of-bed activities such as using a wheelchair. In the evaluation of cognition, the difference between 8 and 9 points on the scale was found to be clinically significant, with 8 points or lower reflecting severe cognitive impairment and 9 points indicating no severe cognitive impairment. Therefore, the developed tool can be considered a valid and useful tool for assessing the RFA of elderly residents based on the composition of its items and its statistical reliability.

However, there are several limitations to the study that should be addressed. We were only able to conduct 197 residents' assessments in total, and additional assessments are thus needed to confirm the results. Additionally, since the type of remaining functional ability is divided into four categories, for robust verification of the RFA's validity, re-verification must be evaluated by verifying the change of remaining functional ability through developing and applying the function focused care intervention program.

This study suggests that our proposed tool is useful for nursing plans for $\mathrm{NH}$ residents. To use it, $\mathrm{RNs}$ require no additional education except to follow its concise guidelines. This tool could be used by RNs in their daily routine in NHs because it only requires 5 to 10 minutes to categorize and evaluate the residents' RFA. The proposed tool has 15 items which are useful for establishing the nursing focus for elderly residents when nurses are planning their nursing care, and helping nurses' daily routine practice of $\mathrm{NH}$ to detect the change of functional ability of $\mathrm{NH}$ residents effectively.

\section{CONCLUSION}

A categorization tool with 15 items used to assess the RFA of NH residents was developed based on the practical experience of $\mathrm{NH}$ nurses. In this study, qualitative 
research was conducted for developing practical validity of the tool and cut points of the tool were derived by statistical relevance and have practical meaning. The proposed tool can be used to promote effective nursing care by improving the RFA of $\mathrm{NH}$ residents and strengthening evidence-based nursing practice guidelines in NHs.

\section{CONFLICTS OF INTEREST}

The author declared no conflict of interest.

\section{AUTHORSHIP}

Study conception and design acquisition - CSO; Data collection $\mathrm{KHJ}$; Analysis and interpretation of the data - KHJ; Drafting and critical revision of the manuscript - $\mathrm{CSO}$ and $\mathrm{KHJ}$

\section{ACKNOWLEDGEMENT}

This papers extracted from a part of the first author's Ph.D. thesis from Korea University. This research was supported by National Research Foundation (NRF-2015R1D1A1A01057258, NRF-2017R1A2 B4007896).

\section{REFERENCES}

1. Cardoso T, Oliveira MD, Barbosa-Póvoa A, Nickel S. Modeling the demand for long-term care services under uncertain information. Health Care Management Science. 2012;15(4):385-412. https://doi.org/10.1007/s10729-012-9204-0

2. Steventon A, Roberts A. Estimating length of stay in publiclyfunded residential and nursing care homes: a retrospective analysis using linked administrative data sets. BMC Health Services Research. 2012;12(1):377-84. https://doi.org/10.1186/1472-6963-12-377

3. Korea Ministry of Health and Welfare. 2016 Current status of elderly facility [Internet]. Sejong: Korea Ministry of Health and Welfare; 2016 [updated 2015 Dec 31; cited 2016 May 17]. Available from:

http://www.index.go.kr/potal/main/EachDtlPageDetail.do ?idx_cd=2766

4. Fusco O, Ferrini A, Santoro M, Monaco MRL, Gambassi G, Cesari M. Physical function and perceived quality of life in older persons. Aging Clinical \& Experimental Research. 2012; 24(1):68-73. https://doi.org/10.1007/BF03325356

5. Korea Ministry of Health and Welfare. Government notice [Internet]. Sejong: Korea Ministry of Government Legislation; 2017 Dec 12 [updated 2017 Dec 12; cited 2018 Dec 23]. Available from:

http://www.law.go.kr/LSW/admRulLsInfoP.do?admRulSeq $=2100000105629$

6. Korea Ministry of Health and Welfare. Government notice 2016-167 [Internet]. Sejong: Korea Ministry of Government
Legislation; 2016 Aug 30 [updated 2016 Aug 30; cited 2018 Dec 23]. Available from:

http://www.law.go.kr/LSW/ / flDownload.do?flSeq=363620 $27 \& f 1 N m=\% 5 B \% E B \% B 3 \% 84 \% \mathrm{EC} \%$ A7 $\% 80+\% \mathrm{EC} \% \mathrm{~A} 0 \% 9 \mathrm{C} 5$

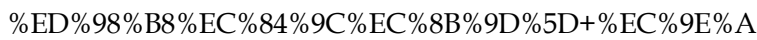
$5 \% \mathrm{EA} \% \mathrm{~B} 8 \%$ B0\%EC $\% 9 \mathrm{~A} \% 94 \% \mathrm{EC} \% 96 \% 91 \% \mathrm{EC} \% 9 \mathrm{D} \% \mathrm{~B} 8 \% \mathrm{E}$ C\%A0\%95\%EC\%A1\%B0\%EC\%82\%AC\%ED\%91\%9C\%0A

7. National Health Insurance Service. 2016 Long-Term Care Insurance Statistical Yearbook. Annual Report. Wonju: National Health Insurance Service; 2017 Jul. Report No. K11-B550928000047-10.

8. Kim HJ, Kim SJ, Kim MS, Choi JE, Chang SO. Guide map for preserving remaining ability of nursing home residents with physical-cognitive functional decline. The Journal of Continuing Education in Nursing. 2017;48(2):73-80. https://doi.org/10.3928/00220124-20170119-08

9. Kim H, Harrington C, Greene WH. Registered nurse staffing mix and quality of care in nursing homes: a longitudinal analysis. The Gerontologist. 2009;49(1):81-90.

https://doi.org/10.1093/geront/gnp014

10. Lim SY, Chang SO, Kim SJ, Kim HJ, Choi JE, Park MS. Nurses' management of nursing home residents' remaining functional ability: concept development. Journal of Korean Academy of Fundamentals of Nursing. 2014;21(1):57-68. https://doi.org/10.7739/jkafn.2014.21.1.57

11. Maxwell JA. Qualitative research design: an interactive approach. 3rd ed. Thousand Oaks, CA: Sage publications; 2012. $219 \mathrm{p}$.

12. Terwee C, Bota S, Boer M, Van Der Windt D, Knol D, Dekker J, et al. Quality criteria were proposed for measurement properties of health status questionnaires. Journal of Clinical Epidemiology. 2007;60(1):34-42. https://doi.org/10.1016/j.jclinepi.2006.03.012

13. Lee YK. Evaluation of validity for Korea's long-term care client selection method: a comparison to Germany and Japan's longterm care client selection method. Social Welfare Policy. 2015; 42(3):271-92. http://210.101.116.14/ftp43/viewer.asp

14. Jung DY, Lee JH, Lee SM. A meta-analysis of fear of falling treatment programs for the elderly. Western Journal of Nursing Research. 2009;31(1):6-16. https://doi.org/10.1177/0193945908320466

15. Yun ES. Fall prediction model for community-dwelling elders based on gender. Journal of Korean Academy of Nursing. 2012;42(6):810-8

https://doi.org/10.4040/jkan.2012.42.6.810

16. Kim YS, Choi-Kwon S. Fall risk factors and fall risk assessment of inpatients. Korean Journal of Adult Nursing. 2013;25(1): 74-82. https://doi.org/10.7475/kjan.2013.25.1.74

17. Greiner M, Pfeiffer D, Smith R. Principles and practical application of the receiver-operating characteristic analysis for 
diagnostic tests. Preventive Veterinary Medicine. 2000;45(1-2): 23-41. https://doi.org/10.1016/S0167-5877(00)00115-X

18. Boltz M, Capezuti E, Shabbat N. Nursing staff perceptions of physical function in hospitalized older adults. Applied Nursing Research. 2011;24(4):215-22.

https://doi.org/10.1016/j.apnr.2010.01.001

19. Resnick B, Galik E, Boltz M. Function focused care approaches: literature review of progress and future possibilities. Journal of the American Medical Directors Association. 2013;14(5):313-8. https://doi.org/10.1016/j.jamda.2012.10.019

20. Ciro CA. Maximizing ADL performance to facilitate aging in place for people with dementia. Nursing Clinics. 2014;49(2): 157-69. https://doi.org/10.1016/j.cnur.2014.02.004

21. Reisberg B, Ferris SH, de Leon MJ, Crook T. The Global Deterioration Scale for assessment of primary degenerative dementia. The American Journal of Psychiatry. 1982;139(9): 1136-9. https://doi.org/10.1176/ajp.139.9.1136

22. Marchant JAM, Williams KN. Memory matters in assisted living. Rehabilitation Nursing. 2011;36(2):83-8. https://doi.org/10.1002/j.2048-7940.2011.tb00070.x

23. Chodosh J, Edelen MO, Buchanan JL, Yosef JA, Ouslander JG, Berlowitz DR, et al. Nursing home assessment of cognitive impairment: development and testing of a brief instrument of mental status. Journal of the American Geriatrics Society. 2008; 56(11):2069-75.

https://doi.org/10.1111/j.1532-5415.2008.01944.x

24. Van Doorn C, Gruber-Baldini AL, Zimmerman S, Hebel JR, Port CL, Baumgarten $\mathrm{M}$, et al. Dementia as a risk factor for falls and fall injuries among nursing home residents. Journal of the American Geriatrics Society. 2003;51(9):1213-8. https://doi.org/10.1046/j.1532-5415.2003.51404.x

25. Scott V, Votova K, Scanlan A, Close J. Multifactorial and functional mobility assessment tools for fall risk among older adults in community, home-support, long-term and acute care settings. Age and Ageing. 2007;36(2):130-9.

https://doi.org/10.1093/ageing/afl165

26. Hajian-Tilaki K. Receiver operating characteristic (ROC) curve analysis for medical diagnostic test evaluation. Caspian Journal of Internal Medicine. 2013;4(2):627-35.

https://www.ncbi.nlm.nih.gov/pmc/articles/PMC3755824 /pdf/cjim-4-627.pdf

27. Lasko TA, Bhagwat JG, Zou KH, Ohno-Machado L. The use of receiver operating characteristic curves in biomedical informatics. Journal of Biomedical Informatics. 2005;38(5):404-15. https://doi.org/10.1016/j.jbi.2005.02.008 